\title{
E06
}

\section{Probabilistic Shale Smear Modelling - Scale Effects on Sealing}

\author{
T. Manzocchi* (University College Dublin), C. Childs (University College \\ Dublin) \& J. Walsh (University College Dublin)
}

\section{SUMMARY}

Sealing effects of multiple shale smears are poorly described by traditional algorithms (e.g. SGR, SSF etc). The newer PSSF algorithm contains a more representative fault rock model, and is directly applicable to some types of fault seal problem at some scales. However, it is an averaging algorithm and explicit objectbased models of shale smears are sometimes required. Both the applicability of the different approaches, and the overall effects of shale smears on across-fault connectivity, are strongly scale-dependent. 


\section{Fault and Top Seals \\ Montpellier 2009}

Faults formed at shallow depths in mixed sandstone / shale sequences contribute to fault seal through the formation of discrete clay smears. Traditionally, the sealing potential of clay smears is addressed through deterministic fault surface proxy-property algorithms such as the shale-layer-specific Clay Smear Potential (CSP) and Shale Smear Factor (SSF) measures, or the more general Shale Gouge Ratio (SGR) measure (e.g. Yielding et al., 1997). Although these have all proven useful in fault seal studies, each approach is based on a particular underlying fault rock model, which can render the algorithms conceptually problematic. For example, there is no unanimity as to how smears deriving from multiple shale beds should be dealt with in the CSP and SSF algorithms, and the inherent averaging of the SGR algorithm apparently has little to do with faults composed of discrete clay smears.

Some of these problems have been resolved by the recent introduction of the Probabilistic Shale Smear Factor (PSSF) measure, which is defined as the probability that a particular position on a fault is free of shale smears (Childs et al., 2007). Smears deriving from multiple beds are implicitly dealt with as the measure describes the absence rather than presence of smears. There is seemingly a direct relationship between PSSF and seal probability at a particular position on a fault. Moreover, despite their very different conceptual background, PSSF and SGR are related directly if fault throw is many times larger than bed thickness.

Underlying the PSSF approach is the recognition that the precise distribution of clay smears on a fault surface is inherently unpredictable, and the algorithm seeks to summarize this uncertainty as a probability. Whilst it is sometimes appropriate to apply this probability directly, there are situations where a probability of sand-on-sand juxtaposition at a point cannot adequately describe the leaking potential of a fault, and explicit models of clay smears are required. The direct applicability of PSSF depends strongly on scale.

Figure 1, for example, shows an Allan diagram of a portion of a fault highlighting shale layers in grey, probabilistically placed shale smears in black, and unhindered sand-on-sand juxtapositions in yellow. PSSF at any position on this fault is ca. 0.2 , yet there is clearly not an $80 \%$ probability that this fault segment is, overall, a seal - any realisation of the fault will yield abundant unsmeared sand-on-sand juxtapositions, and if a sealing fault is defined as one with no sand-on-sand juxtaposition then there is an almost zero probability that this is a sealing fault. However, if the stratigraphy in Figure 1 is at a scale that is averaged within the height and width of a cell in a reservoir flow simulation model, then a fault transmissibility multiplier equal to PSSF may be entirely appropriate on this fault since, overall, $20 \%$ of the sands communicate across the fault. The larger the ratio between fault throw and bed thickness, the closer the relationships between PSSF and the outcome of any individual model.

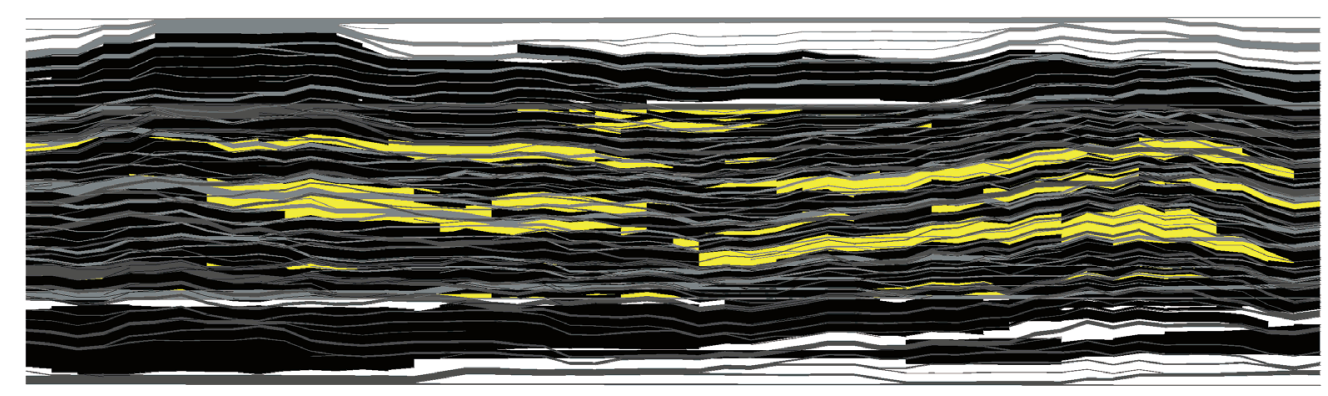

Figure 1 Allan Diagram of a constant-throw fault in a model of an $80 \%$ net:gross sequence of poorly amalgamated beds. Shale smears with a critical Shale Smear Factor of 8 are placed at a random position between the shale source beds. Shale beds are shown in grey, and shale smear are in black. 


\section{Fault and Top Seals \\ Montpellier 2009}

A number of complications also arise from applying essentially one-dimensional conceptualisations of shale smears, such as the SSF algorithm used to calculated PSSF, to two-dimensional surfaces. For example, if the plunge of a sand-on-sand juxtaposition is at a higher angle to the plunge of individual shale smears, there is a higher probability that somewhere within the juxtaposition there will be an unsmeared window. This is why, if each sand in Figure 1 is a potentially isolated fault-bounded trap, the probability that each trap is sealed by the fault is less than $80 \%$. In this case it is therefore necessary to consider objectbased models of clay smears on fault surfaces (e.g. Manzocchi et al. 2007).

Different scales of problem require different approaches, and in some situations it is necessary to model shale smears explicitly on fault surfaces which in other cases an average property can be calculated and used. The averaging effects of increasing the fault throw to bed thickness ratio and the fault length to bed length ratio can also have a significant effect on the overall sandstone connectivity in a faulted system. In Figure 2, for example, the size (length and throw) of faults relative to the size of beds has a profound effect on overall connectivity, with sub-seismic faults connecting up a disconnected sandstone stratigraphy despite the shale smears, while large, seismically visible faults containing shale smears modelled in exactly the same way disconnect the sands.
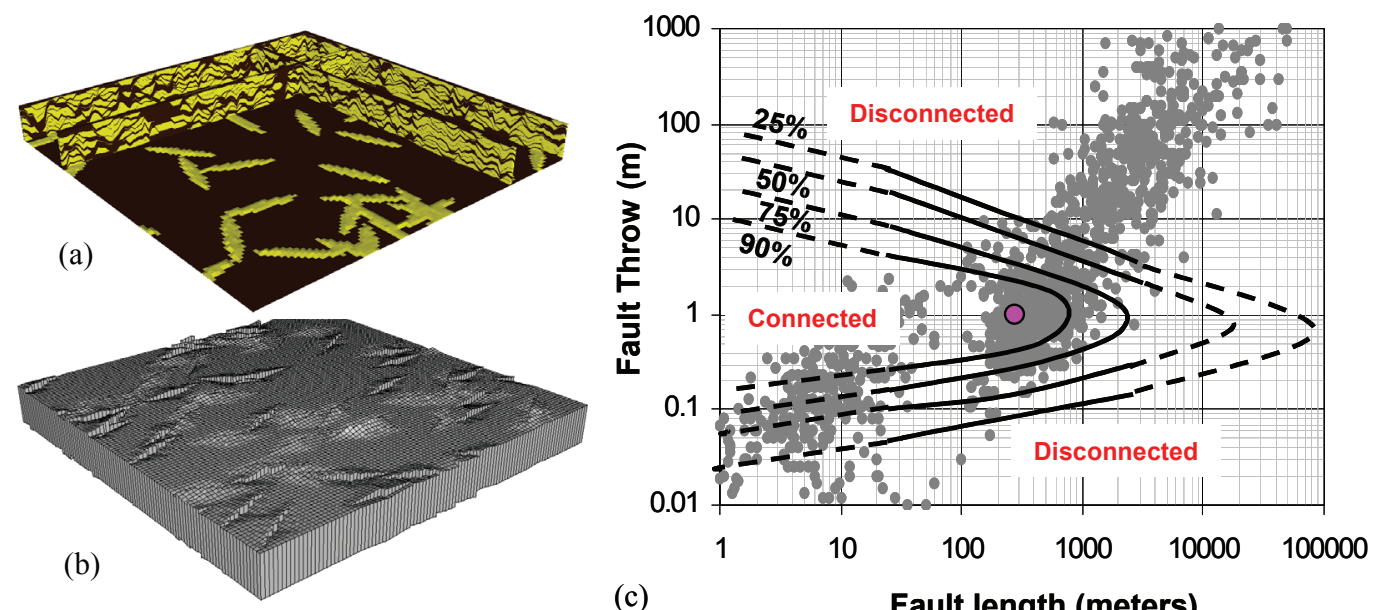

(c)

Fault length (meters)

Figure 2 (a) Idealized system of elongate beds (1m thick, $200 \mathrm{~m}$ wide) with $50 \%$ net:gross ratio and $20 \%$ amalgamation ratio. When unfaulted the sandstone beds are, by and large, mutually disconnected. (b) fault system with fault of a comparable size to the beds in (a). Applying this fault system, with shale smears modelled with critical smear factors of 10, results in the sands becoming mutually connected. (c) Contours of sandstone connectivity as a function of the throw and length of faults for the sedimentological system shown in (a). Natural faults are shown by grey dots, and the faults in (b) are the pink dot. Faults of a comparable size to beds increase connectivity, while larger faults decrease it for the same shale smear characteristics.

Childs C., Walsh, J. J., Manzocchi, T., Strand, J. A., Nicol, A., Tomasso, M., Schöpfer, M.P.J., and Aplin, A. 2007. Definition of a fault permeability predictor from outcrop studies of a faulted turbidite sequence, Taranaki, New Zealand. In: In: Jolley, S. J., Barr, D., Walsh, J. J. \& Knipe, R. J.(eds) Structurally Complex Reservoirs. Geological Society, London, Special Publications, 292, 235-258.

Manzocchi, T., Walsh, J.J., Strand, J., Tomasso, M., Childs, C., \& Haughton, P. 2007. Static and dynamic connectivity in bed-scale models of faulted and unfaulted turbidites. In: In: Jolley, S. J., Barr, D., Walsh, J. J. \& Knipe, R. J.(eds) Structurally Complex Reservoirs. Geological Society, London, Special Publications, 292, 309-336.

Yielding, G., Freeman, B. and Needham, D. T. 1997. Quantitative fault seal prediction. Bulletin of the American Association Petroleum Geologists 81, 897-917. 